\title{
Is gluteus medius injured in patients treated with a trochanter tip entry intramedullary nail? Clinical, electrophysiological and functional outcomes
}

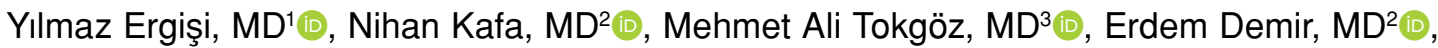 \\ Zeynep Hazar Kanık, MD²D, Erdem Aras Sezgin, MD(D, Muhammet Baybars Ataoğlu, MD $^{3} \mathbb{D}$ \\ ${ }^{1}$ Department of Orthopaedics and Traumatology, Sungurlu State Hospital, Çorum, Turkey \\ ${ }^{2}$ Department of Physiotherapy Rehabilitation, Gazi University, Faculty of Health Sciences, Ankara, Turkey \\ ${ }^{3}$ Department of Orthopaedics and Traumatology, Gazi University Faculty of Medicine, Ankara, Turkey
}

A great portion of femoral shaft fractures require surgical intervention; these fractures are treated with intramedullary nailing (IMN) mostly and in the past 25 years, intramedullary fixation of femoral shaft fractures has gained widespread acceptance as the surgical techniques and implants have steadily improved..$^{[1]}$

Piriform fossa and greater trochanter tip have been described as entry points for the antegrade femoral nailing. With piriform fossa option, the entry axis is aligned with the femoral shaft, which is the advantage of the technique. For disadvantages; this technique threatens the integrity of femoral circumflex artery and superior gluteal nerve, there is need for dissection of abductor and external rotary muscles, there is an increased risk of iatrogenic femoral neck fractures and finally there are difficulties encountered during the approach and placement of guide wire due to position. ${ }^{[2]}$ On the other hand, greater trochanter entry option excels with the ease it brings to the

Received: March 13, 2020

Accepted: April 29, 2020

Published online: June 18, 2020

Correspondence: Mehmet Ali Tokgöz, MD. Gazi Üniversitesi Tıp Fakültesi, Ortopedi ve Travmatoloji Anabilim Dalı,

06500 Teknikokullar, Ankara, Turkey.

E-mail: m.alitokgoz@gmail.com

Doi: $10.5606 /$ ehc. 2020.74801

Citation: Ergiși Y, Kafa N, Tokgöz MA, Demir E, Hazar Kanık Z, Sezgin EA, et al. Is gluteus medius injured in patients treated with a trochanter tip entry intramedullary nail? Clinical, electrophysiological and functional outcomes. Jt Dis Relat Surg 2020;31(2):312-319

\section{ABSTRACT}

Objectives: This study aims to assess the functional outcomes, static-dynamic postural stability of patients and evaluate electromyographic activity of gluteus medius (GMed) muscle during gait and spatiotemporal parameters of gait in patients after antegrade intramedullary nailing (IMN) of femoral shaft fractures with trochanter tip entry.

Patients and methods: Sixteen patients ( 15 males, 1 female; mean age $34.8 \pm 15.2$ years; range, 18 to 58 years) who were treated with an antegrade trochanteric IMN between January 2009 and July 2013 and eight healthy male controls (mean age 39.3 \pm 9.8 years; range, 27 to 57 years) were included in this retrospective study. Muscle strength, static and dynamic postural stability and fall risk were evaluated. In addition, spatiotemporal parameters of gait were assessed using a validated wireless inertial sensing device and a wireless electromyography (EMG) device was used to measure electromyographic activity of GMed muscle in both groups.

Results: There were significant differences in muscle strength, functional and dynamic balance test scores between operated and intact sides (one-leg hop test score $\mathrm{p}=0.009$, balance test scores $\mathrm{p}<0.001-0.033)$. There were significant differences in functional and quality of life physical function test scores between groups (one-leg hop test score $\mathrm{p}=0.014$ ). However, no significant differences were found in EMG results, dynamics balance, and statics postural stability test scores between groups ( $p>0.05$ )

Conclusion: After isolated femur fracture, patients treated with antegrade trochanteric IMN demonstrated good static and dynamic stability and poor functional outcomes compared to controls. In conclusion, patients with antegrade trochanteric IMN have good balance but poor functional performance; however, further studies are needed to find out the primary reason for these results.

Keywords: Antegrade femoral nail, electromyography, femoral fractures, gait analysis, postural balance.

technique particularly in the obese patients, allowing lower complication risks, and less threat to abductor muscles, medial circumflex femoral artery and the 
capsule. ${ }^{[3,4]}$ Furthermore, antegrade method brings along some problems such as postoperative proximal hip pain, trochanteric fracture and heterotopic ossifications, loss of abduction strength and varus alignment deformity. ${ }^{[5,6]}$

Balance is a vital component for performing many activities of daily life. It has been shown that impaired balance develops a predisposition to lower limb injury, risk of falls and asymmetry in lower limb muscle strength. ${ }^{[7,8]}$ Most current studies in the literature are focused on abductor muscle strength and assessments of functional status only performed by questionnaires. There are a few data that evaluate dynamic hip abductor weakness during gait, particularly gluteus medius (GMed) muscle activity. ${ }^{[0]}$

Therefore, in this study, we aimed to assess the functional outcomes, static-dynamic postural stability of patients and evaluate electromyographic activity of GMed muscle during gait and spatiotemporal parameters of gait in patients after antegrade IMN of femoral shaft fractures with trochanter tip entry.

\section{PATIENTS AND METHODS}

A retrospective review of the orthopedics and traumatology department database of Gazi University Faculty of Medicine was conducted to identify the patients who sustained an isolated femoral shaft fracture. Sixteen subjects (15 males, 1 female; mean age $34.8 \pm 15.2$ years; range, 18 to 58 years) with body mass index (BMI) of $23.4 \pm 5.0 \mathrm{~kg}$ who underwent isolated femoral shaft fracture surgery with expert lateral femoral nail between January 2009 and July 2013 (DePuy Synthes; Raynham, Massachusetts, USA) and eight extremities of healthy male controls (mean age $39.3 \pm 9.8$ years; range, 27 to 57 years) according to dominance ratio of study group with BMI of $26.2 \pm 5.0 \mathrm{~kg}$ participated in the study. Five participants' operated side was the dominant side and eleven participants' operated side was the non-dominant side. Patients were not included if the fracture was open, pathological or if there were associated musculoskeletal injuries or multiple system injuries and also if they had previous lower extremity surgery. All participants were invited to the orthopedics and traumatology clinic walking analysis unit and evaluated simultaneously by physiotherapists and orthopedic surgeons. The study protocol was approved by the Gazi University Faculty of Medicine Ethics Committee (Date: 23 June 2014, Decision No: 332). A written informed consent was obtained from each participant. The study was conducted in accordance with the principles of the Declaration of Helsinki.
Mean follow-up time of patients was 21 months (range, 12 to 60 months). In both extremities, limb length was evaluated clinically and radiologically by measuring the distance from anterior superior iliac spine to medial malleolus. All measurements were performed three times and the mean of the three values was presented.

Hip flexors, abductors, external and internal rotators' strength were assessed with the use of a Lafayette Manual Muscle Tester (Lafayette Instruments; Lafayette, Indiana, USA). Particularly the GMed strength was evaluated by placing the subject in side-lying and having him/her abduct and slightly extend the hip while keeping the pelvis rotated slightly forward. Resistance was applied at the ankle. ${ }^{[10]}$ All other assessments of hip were consistent with those described by Hislop and Montgomery. ${ }^{[11]}$ As a functional measure of GMed strength, the Trendelenburg sign was evaluated. Participants stood with the physiotherapist behind them, observing the iliac crests visually and with palpation, and were said to lift one foot off the ground by flexing the hip.

A wireless electromyography (EMG) BTS FreeEMG 300 measurement system (BTS, Inc., Milan, Italy) was used to measure electromyographic activity of GMed muscle during walking. Bipolar adhesive surface electrodes (Noraxon Dual Electrodes, Ag-AgCl, spacing $2.0 \mathrm{~cm}$, Noraxon USA, Inc, Scottsdale, AZ, USA) were placed over GMed muscle. Data were collected by placing electrodes as described by Dondelinger over GMed; the GMed electrode was placed parallel to the muscle fibers over the proximal third of the distance between the iliac crest and greater trochanter. To reduce the resistance of the skin to the electromyographic signal, each subject (when appropriate) had the area shaved of hair with a disposable razor, and then skin was cleaned with an alcohol swab. To observe the maximum isometric contraction for each muscle, the participants were placed into the muscle strength test position and their maximum contraction during tester-induced resistance was recorded. ${ }^{[12]}$ Maximum voluntary isometric contraction (MVIC) for each subject was established by measuring the average peak EMG activity over three trials of a resisted isometric contraction, as a measure of each muscle's maximal strength. In addition, the percentage of MVIC for GMed was collected during three repetitions of walking. The highest percentage of MVIC of GMed was used to establish the average values for statistical analysis. The sampling frequency was 1,000 Hz. 
The measured raw data were band-pass filtered at a bandwidth of $20-500 \mathrm{~Hz} \cdot{ }^{[13,14]}$

Spatiotemporal parameters of gait were assessed using a validated wireless inertial sensing device (GSensor1, BTS Bioengineering S.p.A., Milan, Italy) that was attached to the subject's waist using a semielastic belt, covering the L4-L5 intervertebral space, so as to obtain the acceleration values for the three anatomical axes, anteroposterior (AP), mediolateral (ML) and vertical. During the measurement, patients stood comfortably with their upper limbs along the trunk. Each patient then walked at a moderate speed (natural speed; walking speed was about $1 \mathrm{~m} / \mathrm{sec}$ ) for a distance of 10 meters, without shoes, starting each time with the dominant leg. Temporal and spatial parameters: stance, swing and double stance phase in percent of gait cycle; step length, step width (in centimeters); cadence (steps per minute) and pelvic movements which were collected during the test were processed using software (BTS G-Walk1, Milan, Italy). ${ }^{[15,16]}$

Static postural stability and fall risk were evaluated by the Biodex Balance System (Biodex Medical Systems Inc., New York, USA). The Postural Stability Test emphasizes a patient's ability to maintain center of balance. Tests were performed while each patient stood on legs, right and left side separately, for 20 seconds with the platform in its most stable position. Three trial repetitions were performed in static position and the patient's performance was noted as a stability index.

It performed in three directions (overall AP and ML). Low values of overall stability index, anteroposterior stability index, and mediolateral stability index define a higher balance level. For fallrisk assessment, the Modified Clinical Test of Sensory Interaction on Balance test protocol was used which includes four conditions. All subjects were tested by a physiotherapist and asked to stand for 30 seconds in each condition. As a result of this assessment, stability index and sway index were measured. ${ }^{[17]}$

The Star Excursion Balance Test is a clinical test designed to detect dynamic balance deficits associated with lower extremity pathology. It is a functional test that requires strength, flexibility, neuromuscular control, balance, stability, and range of motion. According to Plisky et al.'s study, ${ }^{[18]}$ we chose three directions (anterior, posteromedial and posterolateral). Patients performed three practices in each direction on each limb. Between trials, 5 seconds were given to patients as a rest time. The physiotherapist marked the point that a subject touched along the line and then manually measured the distance in centimeters from the center of the grid to the touch point with a tape measure. Reach distances were then normalized to participants' leg length, which was measured from the anterior superior iliac spine to the distal tip of the medial malleolus. ${ }^{[18,19]}$

One-leg hop for distance test was used as functional assessment. The subject began the hop for distance standing on one leg and jumped forward as far as possible. The subject was expected to perform a controlled landing. The test was performed three times for each leg. The distance in centimeters was measured. ${ }^{[20,21]}$

For functional evaluations, Lower Extremity Functional scale (LEFS) and Hip Disability and Osteoarthritis Outcome Score (HOOS) were used. These self-administrated health status questionnaires intended to assess the overall functional status of the patients. Both questionnaires have Turkish versions. ${ }^{[22,23]}$ Also, patients were evaluated with the Short Form 36 (SF-36) which is a generic measure of health status that is applicable to all patient populations to assess patients' quality of life.

\section{Statistical analysis}

All data were analyzed using the IBM SPSS, version 20.0 software (IBM Corp., Armonk, NY, USA). The variables were investigated using visual (histograms, probability plots) and analytical methods (Kolmogorov-Smirnov/Shapiro-Wilks test) to determine whether or not they were normally distributed. Demographic data of femur shaft fracture patients and controls were compared with MannWhitney $U$ test and expressed in 95\% confidence interval. There was no statistical difference between dominant and non-dominant sides in terms of all the evaluated parameters, so only non-dominant sides of the controls were used for analysis. Since data of measurement outcomes were not normally distributed, data of patients and healthy control group and also patients' both extremities were compared with Mann-Whitney $U$ test and expressed in median and interquartile range (IQR). Statistical significance was set at $\mathrm{p}<0.05$.

\section{RESULTS}

The demographic and clinical characteristics of the study population were shown in Table I. Ten from 16 patients reported activity pain. The average severity of pain was reported as mild (median: 2.5-IQR: 0-5 on the visual analog scale). Despite the pain, all patients were able to return to their usual work. 


\begin{tabular}{|c|c|c|c|c|}
\hline \multicolumn{5}{|c|}{$\begin{array}{l}\text { TABLE I } \\
\text { Demographic and clinical characteristics of st }\end{array}$} \\
\hline & \multicolumn{2}{|c|}{ Study group } & \multicolumn{2}{|c|}{ Control group } \\
\hline & $\mathrm{n}$ & Mean \pm SD & $\mathrm{n}$ & Mean $\pm S D$ \\
\hline Age (year) & & $34.8 \pm 15.2$ & & $39.3 \pm 9.8$ \\
\hline Body mass index $\left(\mathrm{kg} / \mathrm{m}^{2}\right)$ & & $23.4 \pm 5.0$ & & $26.2 \pm 5.0$ \\
\hline Operated side & & & - & \\
\hline Right & 6 & & & \\
\hline Left & 10 & & & \\
\hline Postoperative (month) & & $21.7 \pm 17.6$ & - & \\
\hline Weight transfer time (month) & & $48.3 \pm 55.1$ & - & \\
\hline
\end{tabular}

The difference in length between extremities was found to be about 0.5 (IQR $(0-1) \mathrm{cm}$ and no significant difference was found compared to controls ( $p>0.05$ ). There were no significant differences in GMed MVIC and MVIC\% values between operated and intact sides and also between groups ( $p>0.05)$ (Table II). There were significant differences in hip internal rotator $(\mathrm{p}=0.015)$ and external rotator $(\mathrm{p}=0.029)$ muscles' strength between operated and intact sides. However, no significant differences were found in hip flexor

\section{TABLE II}

Comparison of MVIC and \% MVIC of gluteus medius values between operated and intact sides; operated side and control group

\begin{tabular}{|c|c|c|c|c|c|c|c|c|}
\hline & \multicolumn{2}{|c|}{$\begin{array}{c}\text { A } \\
\text { Operated side }\end{array}$} & \multicolumn{2}{|c|}{$\begin{array}{c}\text { B } \\
\text { Intact side }\end{array}$} & \multirow[b]{2}{*}{$p^{A-B}$} & \multicolumn{2}{|c|}{$\stackrel{\text { C }}{\text { Control group }}$} & \multirow[b]{2}{*}{$p^{A-C}$} \\
\hline & Median & IQR & Median & IQR & & Median & IQR & \\
\hline Gluteus medius (MVIC) & 19.96 & $19.71-20.42$ & 20.40 & $19.47-20.67$ & 0.285 & 20.38 & $19.86-20.71$ & 0.288 \\
\hline $\begin{array}{l}\text { Gluteus medius MVIC\% during } \\
\text { walking }\end{array}$ & 0.67 & $0.43-0.84$ & 0.88 & $0.62-1.97$ & 0.137 & 0.63 & $0.51-0.81$ & 0.880 \\
\hline
\end{tabular}

MVIC: Maximum voluntary isometric contraction; IQR: Interquartile range; $\mathrm{p}^{A-B}$ : Mann-Whitney $\mathrm{U}$ test between operated and intact sides; $\mathrm{p}^{A-C}$ : Mann-Whitney $\mathrm{U}$ test between operated side and control group.

\begin{tabular}{|c|c|c|c|c|c|c|c|c|}
\hline \multicolumn{9}{|c|}{$\begin{array}{c}\text { TABLE III } \\
\text { Comparison of strength of hip muscles and spatiotemporal gait parameters } \\
\text { operated side and control group }\end{array}$} \\
\hline & \multicolumn{2}{|c|}{$\begin{array}{c}\text { A } \\
\text { Operated side }\end{array}$} & \multicolumn{2}{|c|}{$\begin{array}{c}\text { B } \\
\text { Intact side }\end{array}$} & \multirow[b]{2}{*}{$p^{A-B}$} & \multicolumn{2}{|c|}{$\begin{array}{c}\text { C } \\
\text { Control group }\end{array}$} & \multirow[b]{2}{*}{$p^{A-C}$} \\
\hline & Median & IQR & Median & IQR & & Median & IQR & \\
\hline Hip flexor & 209 & $175-235$ & 224 & $205-246$ & 0.305 & 295 & 292-329 & $<0.001^{*}$ \\
\hline Hip abductor & 225 & $165-266$ & 240 & $203-321$ & 0.196 & 347 & $336-383$ & $<0.001^{*}$ \\
\hline Hip internal rotator & 105 & $77-121$ & 121 & $109-162$ & $0.015^{\star}$ & 178 & $156-186$ & $<0.001^{*}$ \\
\hline Hip external rotator & 105 & $82-134$ & 130 & $115-145$ & $0.029^{*}$ & 168 & $162-175$ & $<0.001^{*}$ \\
\hline Quadriceps femoris & 105 & $167-221$ & 202 & $178-252$ & 0.210 & 297 & $229-369$ & $0.005^{\star}$ \\
\hline Step length & 49.30 & $47.3-50.9$ & 50.7 & $49.1-52.7$ & 0.071 & 49.45 & $48.95-50.2$ & 0.548 \\
\hline Stance duration & 60.1 & $57.5-62.5$ & 60.7 & $59.6-62.9$ & 0.503 & 61.15 & $59.7-62.7$ & 0.548 \\
\hline Swing duration & 39.9 & $37.5-42.5$ & 39.3 & $37.1-40.4$ & 0.484 & 38.85 & $37.3-40.3$ & 0.238 \\
\hline Pelvic anteroposterior & 2.9 & 2.2-3.9 & 3.3 & $2.1-4.4$ & 0.214 & 3.05 & $2.5-4$ & 0.945 \\
\hline Pelvic mediolateral & 3.6 & $2.5-6.3$ & 4.4 & $3-5.7$ & 0.051 & 5.6 & $5-7$ & 0.115 \\
\hline Pelvic rotation & 8.4 & $5.3-10.4$ & 8.5 & $6.3-9.8$ & 0.113 & 9.85 & $7.9-11.1$ & 0.169 \\
\hline
\end{tabular}




\begin{tabular}{|c|c|c|c|c|c|}
\hline Comparison of $\mathrm{c}$ & leasures betw & $\begin{array}{l}\text { ABLE IV } \\
\text { rated and int }\end{array}$ & es; oper & side and contr & \\
\hline & $\begin{array}{c}\text { A } \\
\text { Operated side }\end{array}$ & $\begin{array}{c}\text { B } \\
\text { Intact side }\end{array}$ & & $\stackrel{\text { C }}{\text { Control group }}$ & \\
\hline & Mean $\pm S D$ & Mean $\pm S D$ & $p^{A-B}$ & Mean $\pm S D$ & $p^{A-C}$ \\
\hline Hip abductor & $267.2 \pm 90.9$ & $302.4 \pm 98.1$ & $0.009^{*}$ & $359.0 \pm 29.7$ & $0.001^{*}$ \\
\hline One-leg hop test & $109.1 \pm 33.5$ & $125.8 \pm 24.3$ & $0.009^{*}$ & $133.2 \pm 17.0$ & $0.014^{*}$ \\
\hline SEBT anterior & $77.4 \pm 18.3$ & $88.0 \pm 10.6$ & $0.008^{*}$ & $80.6 \pm 9.0$ & 0.834 \\
\hline SEBT posteromedial & $122.8 \pm 18.7$ & $82.7 \pm 10.8$ & $<0.001^{*}$ & $126.7 \pm 12.9$ & 0.579 \\
\hline SEBT posterolateral & $75.5 \pm 15.4$ & $79.3 \pm 14.2$ & $0.033^{*}$ & $76.0 \pm 18.4$ & 0.769 \\
\hline Overall index & $0.9 \pm 0.8$ & $1.0 \pm 0.8$ & 0.510 & $0.7 \pm 0.3$ & 0.837 \\
\hline Anteroposterior index & $0.7 \pm 0.8$ & $0.7 \pm 0.7$ & 0.375 & $0.5 \pm 0.1$ & 0.945 \\
\hline Mediolateral index & $0.4 \pm 0.2$ & $0.5 \pm 0.4$ & 0.389 & $0.4 \pm 0.3$ & 0.680 \\
\hline
\end{tabular}

SD: Standard deviation; SEBT: Star Excursion Balance test; ${ }^{*} \mathrm{p}<0.05 ; \mathrm{p}^{\mathrm{A}-\mathrm{B}}$ : Mann-Whitney U test between operated and intact sides; $\mathrm{p}^{\mathrm{A} \cdot \mathrm{C}:}$ : MannWhitney $\mathrm{U}$ test between operated side and control group.

( $\mathrm{p}=0.305)$, hip abductor $(\mathrm{p}=0.196)$ and knee extensor $(\mathrm{p}=0.210)$ muscles' strength between operated and intact sides (Table III).

There were significant differences in hip flexor $(p<0.01)$, abductor $(p<0.01)$, internal rotator $(p<0.01)$, external rotator $(\mathrm{p}<0.01)$ and knee extensor $(\mathrm{p}=0.005)$ muscles' strength between the study and control groups. No significant differences were determined in spatiotemporal gait parameters and pelvic motions between operated and intact sides and also between groups $(p>0.05)$ (Table III). None of the patients demonstrated Trendelenburg sign.

Scores for the SF-36 physical component was median: 46.95 (IQR: 40.95-53.45) in the study group and median: 54.4 (IQR: 52.9-58.7) in the control group. The difference between groups was statistically significant $(\mathrm{p}=0.039)$.

There were significant differences in functional and dynamic balance test scores between operated and intact sides (one-leg hop test score $\mathrm{p}=0.009$, Star Excursion Balance Test scores anterior direction $\mathrm{p}=0.008$, posteromedial direction $\mathrm{p}<0.001$,

\begin{tabular}{|c|c|c|c|}
\hline \multicolumn{4}{|c|}{$\begin{array}{c}\text { TABLE V } \\
\text { Comparison of functional outcome measures between study } \\
\text { and control groups }\end{array}$} \\
\hline & Study group & Control group & \\
\hline & Mean $\pm S D$ & Mean $\pm S D$ & $p$ \\
\hline HOOS & $22.8 \pm 19.4$ & $25.0 \pm 4.6$ & $0.004^{*}$ \\
\hline LEFS & $61.0 \pm 13.7$ & $75.8 \pm 6.1$ & $0.003^{*}$ \\
\hline
\end{tabular}

posterolateral direction $\mathrm{p}=0.033$ ). There were no significant differences in statics postural stability scores (one-leg scores overall $\mathrm{p}=0.510$, anteroposterior $\mathrm{p}=0.375$, mediolateral $\mathrm{p}=0.389$ ) between operated and intact sides (Table IV). There were significant differences in functional and quality of life physical function test scores between groups (one-leg hop test score $\mathrm{p}=0.014$, HOOS $\mathrm{p}=0.004$, LEFS score $\mathrm{p}=0.003$ ). However, no significant differences were found in dynamics balance and statics postural stability test scores between groups ( $>0.05)$ (Table V).

\section{DISCUSSION}

In the current study, statistically significant differences were found in hip abductor muscle strength, dynamic balance and functional performance scores compared to the healthy contralateral side of patients, after a mean follow-up of 21 months. Compared to the control group, we observed significant differences only in hip abductor muscle strength, performance and questionnaire results.

When attempting to determine muscle strength using Lafayette muscle dynamometer in the current study, compared to uninjured leg, only hip internal and external rotator muscles' strength were significantly decreased. However, compared with the normal controls, the statistically significant findings were slight weakness of hip abductors, hip flexors, and hip internal and external rotators in the injured limbs. That result could be interpreted as the patients' avoidance of using the operated limb and overall limiting their own activity, rather than surgery or causes related to the initial trauma. 
In the current study, according to the Star Excursion Balance Test which evaluates dynamic balance, statistically significant disparity was observed on all three planes (anterior, posteromedial and posterolateral) between the operated side and the healthy controlateral side. It was also previously reported that there were functional differences between the extremities after tibia fracture. ${ }^{24]}$ Still, when the static postural stability scoring was evaluated, no statistically significant disparity was found on either anteroposterior or mediolateral swings, between sides. However, compared with the control group, no significant difference was observed on dynamic balance and static postural stability results. In light of these studies, it may be concluded that with the trochanteric tip entry nail technique, dynamic balance was affected by abductor function impairment at the second year postoperatively. Nevertheless, no difference was observed on the test scores compared with the control group. The difference between the affected limb and the unaffected limb could have resulted from excessive use of intact side in the post-traumatic period increasing the stability of the intact side. However, balance functions could approach normal within two years after the operation.

Controversial outcomes have been reported about functional results after femoral shaft fracture. Successful results have been reported more frequently in non-comparative studies, ${ }^{[25,26]}$ while other studies have reported functional losses. It was stated that quadriceps muscle strength and functional status of patients decreased after femoral fractures in both adult and underage populations like in the present study. ${ }^{[27,28]}$ In one-leg hop test, a significant drop was observed in functional performance of patients who underwent antegrade nailing procedure with greater trochanter entry after a femoral shaft fracture. Lower Extremity Functional scale and HOOS questionnaires were used and the results, compared with the control group, were found to be lower, consistent with functional test results. Low functional scores seen in patients might be associated with GMed weakness or patients' inability to trust their operated extremity.

Abductor weakness was identified in the antegrade nail treatment group and attributed to the hip abductor muscle and gluteal nerve damage occurring during the operation. ${ }^{[9]}$ Decreased muscular strength of hip abduction is possibly triggered by damage of GMed insertion side on the greater trochanter with the use of the trochanter tip as an entry point for the nail insertion, as it was used in our study. ${ }^{[29]}$ In a meta-analysis study, femoral nails with piriformis fossa entry and nails with trochanter major entry were compared and it was reported that nails with trochanter major entry had better functional results. However, in this study, the functional evaluation was performed using only Harris hip scores and the patients with trochanter major entry nails were not compared with unaffected limbs or healthy adults. ${ }^{[30]}$ In our study, functional results were evaluated by both scales and also with measurable, repeatable and continuous variables, and functional results were interpreted by comparison with healthy adults.

In a study about femoral nails, when the GMed was evaluated with static EMG, muscle damage was detected in eight of 19 patients. ${ }^{[31]}$ However, no difference was found in MVIC values in both static EMG (on table) and dynamic EMG (during walking) in present study. In addition, gait analysis did not demonstrate any significant changes in step length, stance and swing durations, pelvic motions, and also it failed to detect any abnormalities in our study group. According to these results, it could be concluded that, contrary to what was expected, the GMed muscle did not suffer any damage and limited abduction motion due to postoperative pain and the incision was the reason for the muscle strength deficiency. In addition, deficient strength has been shown on the muscles of the hip when investigated with manual muscle strength, though no difference was observed neither in electromyographic evaluations nor gait parameters. That kind of result might be seen owing to the muscle strength evaluation being performed with a manual muscle test device.

To the best of our knowledge, this was the first study documenting GMed electromyographic activity during walking and gait analysis of patients undergoing antegrade femoral nailing of isolated femoral shaft fractures with trochanter tip entry. The main limitations of the present study were its retrospective nature and the limited sample size. However, the strengths of this study were the development of a protocol for the appropriate measurement of excessively various outcomes which include balance assessment, electromyographic evaluations and gait analysis. There were two other limitations of the study design. Firstly, all surgeons acted in accordance with the surgical guidelines of implant; however, the surgeries were not performed by the same surgeon. Secondly, despite the fact that the dominant side information of the patients was given and a similar group was formed according to the ratio of the dominant side of the study group while forming the control group, there was no regression 
analysis related to the dominant side data between control and study groups.

In conclusion, in patients who underwent antegrade nailing with greater trochanter entry technique after femoral shaft fractures, while the static balance is unaffected, hip abductor muscle strength, dynamic balance and functional performance were decreased while GMed MVIC values and gait parameters were similar with controls. This might well be owed to the surgery technique, though it also could be due to the patients' being unable to use the affected part effectively because of pain-related fear. Our study results provided preliminary information for forthcoming prospective, randomized clinical trials with larger sample sizes.

\section{Declaration of conflicting interests}

The authors declared no conflicts of interest with respect to the authorship and/or publication of this article.

\section{Funding}

The authors received no financial support for the research and/or authorship of this article.

\section{REFERENCES}

1. Baki ME, Aldemir C, Duygun F, Doğan A, Kerimoğlu G. Comparison of non-compression and compression interlocking intramedullary nailing in rabbit femoral shaft osteotomy model. Eklem Hastalik Cerrahisi 2017;28:7-12.

2. Ansari Moein $\mathrm{CM}$, Verhofstad MH, Bleys RL, van der Werken C. Soft tissue injury related to choice of entry point in antegrade femoral nailing: piriform fossa or greater trochanter tip. Injury 2005;36:1337-42.

3. Ricci WM, Gallagher B, Haidukewych GJ. Intramedullary nailing of femoral shaft fractures: current concepts. J Am Acad Orthop Surg 2009;17:296-305.

4. Ostrum RF, Marcantonio A, Marburger R. A critical analysis of the eccentric starting point for trochanteric intramedullary femoral nailing. J Orthop Trauma 2005;19:681-6.

5. Ricci WM, Schwappach J, Tucker M, Coupe K, Brandt A, Sanders R, et al. Trochanteric versus piriformis entry portal for the treatment of femoral shaft fractures. J Orthop Trauma 2006;20:663-7.

6. Konya MN, Aslan A, Bakbak S. How is hip prosthesis and proximal femoral nail stability affected by lesser trochanter fractures: A comparative finite element analysis. Eklem Hastalik Cerrahisi 2018;29:79-86.

7. Fort-Vanmeerhaeghe A, Gual G, Romero-Rodriguez D, Unnitha V. Lower limb neuromuscular asymmetry in volleyball and basketball players. J Hum Kinet 2016;50:135-43.

8. Parsa M, Rahimi A, Noorizadeh Dehkordi S. Studying the correlation between balance assessment by Biodex Stability System and Berg Scale in stroke individuals. J Bodyw Mov Ther 2019;23:850-4.

9. Archdeacon M, Ford KR, Wyrick J, Paterno MV, Hampton $\mathrm{S}$, Ludwig $\mathrm{MB}$, et al. A prospective functional outcome and motion analysis evaluation of the hip abductors after femur fracture and antegrade nailing. J Orthop Trauma 2008;22:3-9.

10. Cooper NA, Scavo KM, Strickland KJ, Tipayamongkol N, Nicholson JD, Bewyer DC, et al. Prevalence of gluteus medius weakness in people with chronic low back pain compared to healthy controls. Eur Spine J 2016;25:1258-65.

11. Hislop H, Montgomery J, editors. Daniels and Worthingham's muscle testing: techniques of manual examination. 7th ed. Philadelphia: WB Saunders; 2002.

12. Dondelinger RM. Electromyography--an overview. Biomed Instrum Technol 2010;44:128-31.

13. Distefano LJ, Blackburn JT, Marshall SW, Padua DA. Gluteal muscle activation during common therapeutic exercises. J Orthop Sports Phys Ther 2009;39:532-40.

14. Van Gelder LH, Hoogenboom BJ, Alonzo B, Briggs D, Hatzel B. EMG Analysis and Sagittal Plane Kinematics of the Two-Handed and Single-Handed Kettlebell Swing: A Descriptive Study. Int J Sports Phys Ther 2015;10:811-26.

15. Bugané F, Benedetti MG, Casadio G, Attala S, Biagi F, Manca $\mathrm{M}$, et al. Estimation of spatial-temporal gait parameters in level walking based on a single accelerometer: validation on normal subjects by standard gait analysis. Comput Methods Programs Biomed 2012;108:129-37.

16. Pau M, Leban B, Collu G, Migliaccio GM. Effect of light and vigorous physical activity on balance and gait of older adults. Arch Gerontol Geriatr 2014;59:568-73.

17. Hinman MR. Factors affecting reliability of the Biodex Balance System: a summary of four studies. J Sport Rehabil 2000;9:240-52.

18. Plisky PJ, Rauh MJ, Kaminski TW, Underwood FB. Star Excursion Balance Test as a predictor of lower extremity injury in high school basketball players. J Orthop Sports Phys Ther 2006;36:911-9.

19. Hertel J, Braham RA, Hale SA, Olmsted-Kramer LC. Simplifying the star excursion balance test: analyses of subjects with and without chronic ankle instability. J Orthop Sports Phys Ther 2006;36:131-7.

20. Kockum B, Heijne AI. Hop performance and leg muscle power in athletes: Reliability of a test battery. Phys Ther Sport 2015;16:222-7.

21. Neeter C, Gustavsson A, Thomeé P, Augustsson J, Thomeé $\mathrm{R}$, Karlsson J. Development of a strength test battery for evaluating leg muscle power after anterior cruciate ligament injury and reconstruction. Knee Surg Sports Traumatol Arthrosc 2006;14:571-80.

22. Yilmaz O, Gul ED, Bodur H. Cross-cultural adaptation and validation of the Turkish version of the Hip disability and Osteoarthritis Outcome Score-Physical function Short-form (HOOS-PS). Rheumatol Int 2014;34:43-9.

23. Citaker S, Kafa N, Hazar Kanik Z, Ugurlu M, Kafa B, Tuna Z. Translation, cross-cultural adaptation and validation of the Turkish version of the Lower Extremity Functional Scale on patients with knee injuries. Arch Orthop Trauma Surg 2016;136:389-95.

24. Warschawski Y, Drexler M, Batko B, Elias S, Goldstein Y, Frenkel Rutenberg T, et al. Correlation between preoperative imaging parameters and postoperative basic kinematicsbased functional outcome in patients with tibial plateau fractures. Clin Biomech 2019;65:87-91.

25. Fan KJ, Chen K, Ma WL, Tian KW, Ye Y, Chen HG, et al. Treatment of multi-segment fracture of complex femoral 
shaft with instrument-assisted reduction combined with intramedullary interlocking nail fixation. Zhongguo $\mathrm{Gu}$ Shang 2018;31:472-6.

26. Khan JA, Singh GP, Pandey A. Outcome of Titanium Elastic Intramedullary Nail in the Treatment of Shaft of Femur Fracture in Children. Kathmandu Univ Med J 2015;13:195-9.

27. Hennrikus WL, Kasser JR, Rand F, Millis MB, Richards KM. The function of the quadriceps muscle after a fracture of the femur in patients who are less than seventeen years old. J Bone Joint Surg [Am] 1993;75:508-13.

28. Larsen P, Elsoe R, Graven-Nielsen T, Laessoe U, Rasmussen $\mathrm{S}$. Decreased muscle strength is associated with impaired long-term functional outcome after intramedullary nailing of femoral shaft fracture. Eur J Trauma Emerg Surg 2015;41:673-81.
29. Noda M, Saegusa Y, Takahashi M, Takada Y, Fujita M, Shinohara I. Decreased postoperative gluteus medius muscle cross-sectional area measured by computed tomography scan in patients with intertrochanteric fractures nailing. J Orthop Surg 2017;25:2309499017727943.

30. Kumar P, Neradi D, Kansal R, Aggarwal S, Kumar V, Dhillon MS. Greater trochanteric versus piriformis fossa entry nails for femur shaft fractures: Resolving the controversy. Injury 2019;50:1715-24.

31. Ansari Moein CM, Ten Duis HJ, Oey PL, de Kort GA, van der Meulen W, van der Werken C. Intramedullary femoral nailing through the trochanteric fossa versus greater trochanter tip: a randomized controlled study with in-depth functional outcome results. Eur J Trauma Emerg Surg 2011;37:615-22. 